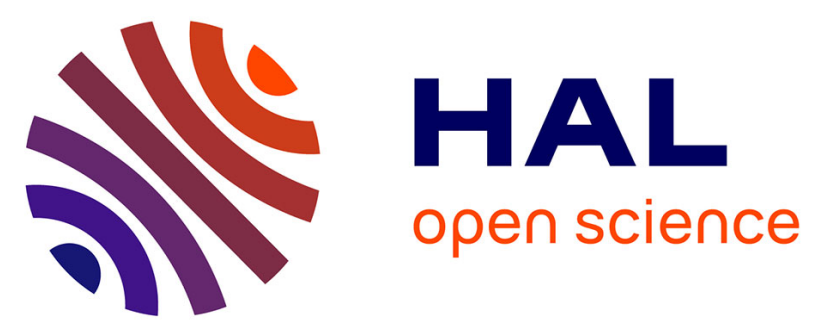

\title{
Effect of Bread Crumb and Crust Structure on the in Vivo Release of Volatiles and the Dynamics of Aroma Perception
}

Solenne Jourdren, Marine Masson, Anne Saint-Eve, Maud Panouille, David Blumenthal, Pascal Lejeune, Isabelle Déléris, Isabelle Souchon

\section{To cite this version:}

Solenne Jourdren, Marine Masson, Anne Saint-Eve, Maud Panouille, David Blumenthal, et al.. Effect of Bread Crumb and Crust Structure on the in Vivo Release of Volatiles and the Dynamics of Aroma Perception. Journal of Agricultural and Food Chemistry, 2017, 65 (16), pp.3330-3340. 10.1021/acs.jafc.7b00287 . hal-01841488

\section{HAL Id: hal-01841488}

https://hal-agroparistech.archives-ouvertes.fr/hal-01841488

Submitted on 17 Jul 2018

HAL is a multi-disciplinary open access archive for the deposit and dissemination of scientific research documents, whether they are published or not. The documents may come from teaching and research institutions in France or abroad, or from public or private research centers.
L'archive ouverte pluridisciplinaire HAL, est destinée au dépôt et à la diffusion de documents scientifiques de niveau recherche, publiés ou non, émanant des établissements d'enseignement et de recherche français ou étrangers, des laboratoires publics ou privés. 
This document is confidential and is proprietary to the American Chemical Society and its authors. Do not copy or disclose without written permission. If you have received this item in error, notify the sender and delete all copies.

\section{Effect of bread crumb and crust structure on the in vivo release of volatiles and the dynamics of aroma perception}

\begin{tabular}{|r|l|}
\hline Journal: & Journal of Agricultural and Food Chemistry \\
\hline Manuscript ID & jf-2017-00287v.R2 \\
\hline Manuscript Type: & Article \\
\hline Date Submitted by the Author: & n/a \\
\hline Complete List of Authors: & $\begin{array}{l}\text { Jourdren, Solenne; UMR GMPA, AgroParisTech, INRA, Université Paris- } \\
\text { Saclay; Lesaffre International } \\
\text { Masson, Marine; UMR GENIAL, AgroParisTech, INRA, Université Paris- } \\
\text { Saclay } \\
\text { Saint-Eve, Anne; UMR GMPA, AgroParistech, INRA, Université Paris-Saclay } \\
\text { Panouille, Maud; AgroParisTech, UMR GMPA } \\
\text { Blumenthal, David; UMR GENIAL, AgroParisTech, INRA, Université Paris- } \\
\text { Saclay } \\
\text { Lejeune, Pascal; Lesaffre International } \\
\text { Deleris, Isabelle; UMR GMPA, AgroParisTech, INRA, Université Paris-Saclay } \\
\text { Souchon, Isabelle; UMR GMPA, AgroParisTech, INRA, Université Paris- } \\
\text { Saclay }\end{array}$ \\
\hline
\end{tabular}

SCHOLARONE

Manuscripts 
Effect of Bread Crumb and Crust Structure on the in vivo Release of Volatiles and the Dynamics of Aroma Perception

Solenne Jourdren ${ }^{a, b}$, Marine Masson ${ }^{c}$, Anne Saint-Eve ${ }^{a}$, Maud Panouillé $^{a}$, David Blumenthal $^{\mathrm{c}}$, Pascal Lejeune ${ }^{\mathrm{b}}$, Isabelle Déléris ${ }^{\mathrm{a}}$, Isabelle Souchon ${ }^{\mathrm{a}}$

aUMR GMPA, AgroParisTech, INRA, Université Paris-Saclay, 78850, Thiverval-Grignon, France

${ }^{\mathrm{b}}$ Lesaffre International, 59700, Marcq-en-Baroeul, France

'UMR GENIAL, AgroParisTech, INRA, Université Paris-Saclay, 91300, Massy, France

Corresponding Author: anne.saint-eve@agroparistech.fr (Anne Saint-Eve), UMR GMPA, AgroParisTech, INRA, Université Paris-Saclay, 78850, Thiverval-Grignon, France, phone: +33 (0)6 1308154 38, fax: +33 (0)130815597 


\section{Abstract}

2 This study examined the effects of bread crumb and crust structure on volatile release 3 and aroma perception during oral processing. French baguettes with different crumb 4 structures were procured from a supermarket or local bakeries $(n=6)$ or produced in the 5 laboratory via par baking $(n=3)$. Eight study participants consumed crumb-only and 6 crumb-and-crust samples, and the resulting volatile release was measured in vivo using 7 proton transfer reaction-mass spectrometry. A statistical model was then used to 8 examine the contributions of volatile compounds to target ion production (i.e., crumb or 9 crust markers). Utilizing the three laboratory-produced breads, chewing behavior and aroma perception were measured via electromyography and the temporal dominance of 11 sensations method, respectively. The results revealed that the initial levels of crumb markers as well as crumb firmness affected crumb markers release. Crust markers were released more quickly than crumb markers, leading to different perception dynamics.

\section{Keywords}

Proton transfer reaction-mass spectrometry (PTR-MS); Aroma release; Bread; Temporal dominance of sensations (TDS); Oral processing 


\section{Introduction}

When a food is being eaten, its aroma compounds are released into the consumer's oral cavity; there, the compounds can interact with olfactory receptors, leading to retronasal aroma perception. ${ }^{1-3}$ Release dynamics depend on food-related physicochemical processes and on consumer-related physiological parameters. Together, these factors determine the quantity and kinetics of the volatile organic compounds (VOCs) released in the oral cavity and thus contribute to how consumers perceive the food they are eating., ${ }^{4,5}$ Therefore it is important to study volatile release during food consumption to better understand aroma perception and its dynamics, the ultimate goal being to create products that meet consumer expectations and match consumer preferences.

In this context, nose-space analyses such as atmospheric pressure chemical ionizationmass spectrometry (APCl-MS) ${ }^{6}$ or proton transfer reaction-mass spectrometry (PTR$M S)^{7}$ are very useful tools to monitor the release of aroma compounds in the air exhaled by a subject consuming food. They have been extensively employed over the past twenty years to study VOC release by different food types. ${ }^{8}$ PTR-MS is a soft chemical ionization technique in which protons are transferred from the protonated reagent, $\mathrm{H}_{3} \mathrm{O}^{+}$, to VOCs that have a greater affinity for protons than does $\mathrm{H}_{2} \mathrm{O} .{ }^{7}$ Although the ionization mainly produces the protonated molecular ion $\mathrm{MH}^{+}$, smaller fragments can also result, especially from alcohols. ${ }^{9}$ For this reason, and because there is no separation step, it is often difficult to identify the fragments yielded by foods with complex volatile profiles. However, despite this limitation, PTR-MS has been described as an efficient method for quantitating the relationship between the volatile fingerprints and sensory characteristics of foods. $^{10-12}$

In particular, PTR-MS has been used to examine differences in VOC release among liquid, semi-solid, and solid foods. Food structure has been found to play an important 
role. For example, liquid foods such as orange or carrot juice tend to release aromas post-swallow, while solid foods such as peanuts or carrot pieces display pre-swallow release. ${ }^{13}$ These results, which are focused on large structural differences, show that it is important to study the impact of structure on VOC release. Furthermore, nose-space analyses have highlighted that there is a large degree of interindividual variability in VOC release profiles, which could be linked to differences in oral processing-including mastication, salivation, and velum opening - that then lead to differences in aroma perception among individuals. ${ }^{14-17}$ This variation must thus be accounted to understand aroma perception.

Bread is a good tool to study the impact of structure on VOC release because of its structural complexity: it is composed of a soft porous crumb surrounded by a rigid crust. In a recent study, the volatile profiles of bread boli collected at three stages of oral processing were analyzed in vitro using PTR-MS. ${ }^{10}$ The results showed that the incorporation of saliva into the boli impeded the release of VOCs. Furthermore, the presence of crust increased the quantity of released ion fragments likely responsible for perceived notes of "roasted cereals" or "cardboard". However, in vitro studies cannot reveal the natural dynamics of VOC release from breads. To date, only one study has followed the in vivo release of VOCs during bread consumption. ${ }^{18}$ It showed that release largely occurred post swallowing. A major constraint is that only one bread type and one subject were used.

The objective of this study was therefore to gain insight into the effect of bread crumb and crust structure on VOC release and aroma perception over the course of oral processing. To this end, a statistical model was used that revealed the contribution of VOCs to the production of key ion fragments observed during nose-space analysis. 


\section{Material and Methods}

\section{Characterizing bread and sample types}

Nine types of French baguettes were used in this study; all had the same composition (white flour, water, yeast, and salt). For these breads, pictures and texture measurements were preliminary performed at different times of purchase before the study to control the stability of production. One came from a supermarket (S), and five came from three local bakeries (b1, b2, and b3). These baguettes fell into two categories: (i) ordinary breads (O), produced using short fermentation times and possibly containing additives, and (ii) traditional breads $(T)$, produced using long fermentation times and containing no additives. ${ }^{19}$ Three other baguettes were produced in the laboratory run by Lesaffre International (B1, B2, and B3; Marcq-en-Baroeul, France), as described in previous studies $^{20,21}$; they were par baked and frozen until usage. Two sample types were studied: crumb only (CO) and crumb with crust (CC). The supermarket/bakery baguettes were used within 4 hours of purchase (which occurred in the morning), and the laboratoryproduced baguettes were used no more than 2 hours after the cooling phase had ended.

The nine baguette types were characterized based on their density, crumb water content, and crumb elasticity as performed in Jourdren et al. (2016). ${ }^{20}$ Bread density was measured using the rapeseed displacement method. Crumb water content was determined by weighing samples before and after oven drying. Crumb elasticity (i.e., Young's modulus) was estimated using compression tests performed on crumb cylinders (h: $2.5 \mathrm{~cm}$; d: $3.0 \mathrm{~cm}$ ) with a TA.XT Plus Texture Analyzer (Stable Micro System, UK). All measurements were performed in triplicate (Table 1).

\section{Monitoring in vivo aroma compound release via PTR-MS}

Preliminary in vitro studies: selection and identification of target ions. An in vitro study was conducted to help select the ions to be monitored by PTR-MS. ${ }^{10}$ The ions were 
selected based on (i) their ability to be detected by in vivo measurements (determined using pretests involving equipment sensitivity) and (ii) their ability to represent sensory differences (Table 2).

To identify these target ions, the VOCs released by the crumbs of 40 French baguettes (the 9 baguette types described above plus 31 additional baguettes obtained from supermarkets and bakeries) were characterized. The 31 additional baguettes were mainly composed of white flour, water, yeast, and salt; they did not contain any sourdough, fat, or sugar. Their in vitro VOC profiles were quantified using two methods: (i) gas chromatography-mass spectrometry (GC-MS) coupled with purge-and-trap extraction and (ii) proton transfer reaction-mass spectrometry (PTR-MS). For both the GC-MS and PTR-MS analyses, the crumbs of each baguette $(n=40)$ were cut into $1-\mathrm{cm}$ squares and frozen at $-80^{\circ} \mathrm{C}$ in glass vials. No replicates were performed in this preliminary study.

In the GC-MS analyses, $5 \mathrm{~g}$ of bread crumb (defrosted at $4^{\circ} \mathrm{C}$ for $15 \mathrm{~h}$ ) were mixed with $10 \mathrm{~mL}$ of Milli-Q water (Merck Milipore, Merck KGaA, Germany) at $4^{\circ} \mathrm{C}$. Five $\mathrm{mL}$ of the mixture, homogenized using a Polytron ${ }^{\odot}$ PT 2100 (VWR, Radnor, USA), were introduced into the sampling tube of a purge-and-trap system, which was heated to $37^{\circ} \mathrm{C}$. A helium purge was run for $20 \mathrm{~min}$ at a flow rate of $20 \mathrm{~mL} / \mathrm{min}$, during which time VOCs were first stripped out from the sample and then retained in a TENAX trap at $40^{\circ} \mathrm{C}$. The trap was subsequently heated to $250^{\circ} \mathrm{C}$ and kept there for 2 min to induce desorption. The VOCs were concentrated in the cryomodule at $150^{\circ} \mathrm{C}$, just before the injection step at $180^{\circ} \mathrm{C}$.

The VOCs were then separated in the chromatography column, ionized by electron impact using GC-MS (6890A Agilent, Santa Clara, USA) and identified with database; the apparatus was equipped with a splitless injector kept at $180^{\circ} \mathrm{C}$ and a CP-Wax $57 \mathrm{CB}$ polar capillary column ( $50 \mathrm{~m} \times 0.25 \mathrm{~mm}$; film thickness of $0.2 \mu \mathrm{m}$; Agilent, Santa Clara, USA). 
121 Helium was the carrier gas (constant flow rate of $1.2 \mathrm{~mL} / \mathrm{min}$ ). Oven temperature 122 increased from $40^{\circ} \mathrm{C}$ to $200^{\circ} \mathrm{C}$ at a rate of $4^{\circ} \mathrm{C} / \mathrm{min}$ and then remained at $200^{\circ} \mathrm{C}$ for $9 \mathrm{~min}$.

123 In the PTR-MS analyses, $5 \mathrm{~g}$ of crumb (frozen at $-20^{\circ} \mathrm{C}$ for $30 \mathrm{~min}$ ) were stored at $20^{\circ} \mathrm{C}$ 124 for one hour in 100-mL Schott flasks that were equipped with valved caps (GL 45, Duran 125 Group, Wertheim, Germany). A highly sensitive PTR-MS apparatus (Ionicon Analytik, 126 Innsbruck, Austria) was used in SCAN mode over a mass range of $m / z 20$ to 200; dwell 127 time was $100 \mathrm{~ms}$ per peak. Five cycles (90 s) were dedicated to measuring the ambient 128 air (i.e., the background signal), and 15 cycles (290 s) were dedicated to measuring the 129 sample headspace. The gas above the samples was introduced into the system through 130 a capillary line heated to $110^{\circ} \mathrm{C}$ at a flow rate of $100 \mathrm{~mL} / \mathrm{min}$. The PTR-MS settings were 131 as follows: $\mathrm{H}_{2} \mathrm{O}$ flow rate of $7.0 \mathrm{~mL} / \mathrm{min}$; drift tube pressure of $200 \mathrm{~Pa}$; drift tube 132 temperature of $60^{\circ} \mathrm{C}$; and drift voltage of $600 \mathrm{~V}(\mathrm{E} / \mathrm{N}=153 \mathrm{Td})$.

133 The PTR-MS dataset was then statistically linked to the GC-MS dataset: the goal was to 134 associate the specific ion fragments detected by PTR-MS with the VOCs identified by 135 GC-MS (see the Data analyses section for more details).

136 In vivo study. A panel of eight volunteers (six women and two men between the ages of 13723 and 34) was recruited from the staff of the Grignon center of the French National 138 Institute for Agricultural Research (INRA) to participate in the in vivo PTR-MS study. They 139 gave their free and informed consent and received compensation for their participation. 140 They were asked not to drink or eat for at least one hour before the sessions. They took 141 part in nine 30-min PTR-MS sessions. One session was dedicated to each baguette type. 142 During the sessions, participants were asked to eat naturally pre-cut CO samples 143 (cylinder: $\mathrm{h}: 2.5 \mathrm{~cm}$; d: $3.0 \mathrm{~cm}$ ) and CC samples (half-cylinder: $\mathrm{h}: 2.5 \mathrm{~cm} ; \mathrm{r}: 3.0 \mathrm{~cm}$ ). 144 Samples were cut from a vertical slice that was $2.5 \mathrm{~cm}$ thick; no more than one minute 
145 passed before the samples were given to the participants. ${ }^{20}$ The participants were asked

146 to rinse their mouths with mineral water (Evian, Danone, France) between sample types.

147 Measuring in vivo dynamics. The in vivo release of aroma compounds was 148 characterized using the multiple ion detection (MID) mode of the PTR-MS apparatus. 149 Three monitoring ions $(m / z 21,37$, and 59$)$ and eight target ions $(m / z 45,47,57,71,73$, 15087,95 , and 97) were studied. Two series of measurements were performed (Table 2). As 151 a result, the cumulative dwell time of a given series was $0.55 \mathrm{~s}$, which did not exceed the 152 expiration time of the participants. ${ }^{22}$ Three replicates were performed for each series.

153 In each series, levels of $\mathrm{m} / \mathrm{z} 21,37$, and 59 were quantified to verify measurement 154 conditions. The $\mathrm{m} / \mathrm{z} 21$ ion, which corresponds to $\mathrm{H}_{3}{ }^{18} \mathrm{O}^{+}$, is the isotopolog of the $\mathrm{m} / \mathrm{z} 19$ 155 reagent ion. It is measured instead of $m / z 19$ to protect the PTR-MS apparatus from 156 excessively high levels of the latter (natural isotopic ratio of ${ }^{18} \mathrm{O} /{ }^{16} \mathrm{O} \approx 0.2$ ). ${ }^{7}$ Humidity 157 levels were checked by monitoring the abundance of the $\mathrm{m} / \mathrm{z} 37$ ion, which must 158 represent less than $2 \%$ of reagent ion signal intensity to limit the background signal. The 159 relative amounts of the $\mathrm{m} / \mathrm{z} 30\left(\mathrm{NO}^{+}\right)$and $32\left(\mathrm{O}_{2}^{+}\right)$ions were considered to be low 160 enough that they did not contribute to ionization. The $\mathrm{m} / \mathrm{z} 59$ ion (resulting from propan-2one protonation) was monitored to trace participant breath. ${ }^{22}$

162 Each in vivo analysis began with a 10-s measurement of ambient air. Then, the breath 163 expired via the participants' noses was measured for $30 \mathrm{~s}$, and they subsequently 164 introduced the samples into their mouths. For each participant, nose air space was 165 sampled by inserting the two inlets of a stainless steel nosepiece into the nostrils. The 166 system was affixed to eyeglasses so that the participants could eat relatively normally. 167 The gas produced by the samples was introduced into the PTR-MS apparatus through a capillary line heated to $110^{\circ} \mathrm{C}$ at a mean flow rate of $85 \mathrm{~mL} / \mathrm{min}$. The PTR-MS settings 
169

170

171

172

173

174

175

176

177

were as follows: $\mathrm{H}_{2} \mathrm{O}$ flow rate of $6.0 \mathrm{~mL} / \mathrm{min}$; drift tube pressure of $200 \mathrm{~Pa}$; drift tube temperature of $60^{\circ} \mathrm{C}$; drift voltage of $600 \mathrm{~V}(\mathrm{E} / \mathrm{N}=152 \mathrm{Td})$.

\section{Characterizing aroma perception dynamics using the temporal dominance of} sensations (TDS) method

Panel. A panel of 14 volunteers was formed (ten women and four men between the ages of 23 and 60 ) by recruiting participants from the PTR-MS study and additional staff from INRA-Grignon. Individuals were invited to join based on their motivation for participating and their aroma discrimination abilities. They gave their free and informed consent and received compensation for their participation. They were asked not to eat or drink for at least one hour before the sessions.

Sensory assessment. All sensory analyses were carried out in individual booths under white light in an air-conditioned room $\left(20^{\circ} \mathrm{C}\right)$. Participants were presented with pre-cut vertical slices of bread $(2.5 \mathrm{~cm}$ thick) placed in plastic boxes labeled with randomly selected three-digit numbers. They were asked to cut a $\mathrm{CO}$ or $\mathrm{CC}$ sample from the vertical slice using the same protocol as in the PTR-MS sessions; they were also instructed to be consistent in their sample cutting. This approach was employed to maximize sample freshness.

After four sessions dedicated to the generation and selection of aroma attributes, a training session was devoted to the temporal dominance of sensations (TDS) test. The participants were introduced to the notion of dominance: a dominant sensation is the sensation that triggers the most attention at a given point in time. ${ }^{23}$ Only six samples (CO and CC samples of B1, B2, and B3) were tested using TDS, which was implemented using Fizz Acquisition software (Version 2.47A, Biosystemes, France). All six samples were tested during a single session; three replicates were performed. The samples were presented in randomized order to the different participants to avoid a bias in the results. 
194 Participants were instructed to click on the "start" button when they introduced the 195 sample into their mouths. Then, they were asked to select its dominant attributes until 196 they could no longer perceive anything, at which point they were to click on the "stop" 197 button. They indicated when they had swallowed the sample by clicking on the "I'm swallowing" button. Four aroma attributes ("wet flour", "fermented”, "wheat”, and "butter") were used in the assessment of the CO samples, and seven ("wet flour", "fermented", "wheat", "roasted cereals", "cardboard", "toasted", and "grilled") were used in the assessment of the CC samples. ${ }^{10}$ The list of attributes was presented in a randomized order to the participants, but the order was always the same for a given participant. To prepare participants for the test, a warm-up sample was introduced at the beginning of each session.

\section{Chewing behavior quantified by electromyography}

206

207

208

Three participants (\#1, \#3, and \#8) were chosen, and their chewing behavior during natural bread consumption was characterized. The same samples were used as in the TDS tests (CO and CC samples of B1, B2, and B3).

The activity of the muscles of mastication (the superficial masseter and the anterior temporalis), which are located on both sides of the face, was recorded using surface electromyography (EMG). Two surface electrodes (F-E5GH model, Astro-Med, USA) were placed $1.5 \mathrm{~cm}$ apart along the length of each of the muscles, which were located via palpation. To minimize electrical background noise, an ear clip electrode (model FE34DG, Astro-Med, USA) was placed on the participant's ear lobe.

The six samples were assessed in triplicate during the same session to avoid any bias linked to electrode positioning. The participants ate pre-cut $\mathrm{CO}$ and $\mathrm{CC}$ samples first and second, respectively; they were asked to chew as naturally as possible. Sample dimensions were the same as in the PTR-MS study. 


\section{Data analyses}

220

Statistical analyses were carried out with Fizz Traitement software (Version 2.47A,

221

Biosystemes, France) for the sensory data and XLStat software (Version 2010.4.02,

222

Addinsoft, France) for other data.

223

Bread properties. A one-way analysis of variance (ANOVA, $p<0.05$ ) followed by a

224

225

226

227

228

229

230

231

232

233

234

235

236

237

238

239

240

241

242 multiple comparisons test (Fisher's LSD test, $p<0.05$ ) was used to assess differences in properties among bread types. A multiple factor analysis (MFA) was used to examine bread structural properties (density, water content, and Young's modulus) and the initial volatile fingerprints (in vitro PTR-MS data) for CO samples for the nine bread types.

Relative contribution of VOCs to target ions. To follow VOCs release and not only fragments, it was necessary to relate with statistical models VOCs and ions. For that, we selected precursors VOCs using the literature and the results of the GC-MS analysis. $^{7,9,24-28}$ The $m / z 47$ and 97 ions can only be produced by the fragmentation of ethanol and furfural, respectively. However, the other ions can result from several different VOCs (ranging from three to ten). Therefore, to identify the VOC that most contributed to producing a given ion, it was assumed that the contribution depended on the amount of the VOC in the sample, VOC volatility, and the VOC's proportion of fragmentation into the target ion. We estimated VOC volatility using Henry's law constant (atm. $\left.\mathrm{m}^{3} / \mathrm{mole}\right)$, which was calculated with the Bond contribution method in $25^{\circ} \mathrm{C}$ water (EPI Suite, US Environmental Protection Agency, USA). We used the VOC's proportion of fragmentation observed in pure solution. ${ }^{7,9,24-28}$ When no $F$ was found in literature, we choose to maximize the contribution of this molecule to 100 . The respective contribution of VOC $x$ to ion $y$ is given by the equation (1):

$$
\% \text { contribution }(x, y)=100 \times \frac{A U C_{x} \times V_{x} \times F_{x, y}}{\sum_{1}^{N} A U C_{i} \times V_{i} \times F_{i, y}}
$$


243 where $\mathrm{N}$ is the number of molecules, AUC is the area under the curve obtained by GC-

$244 \mathrm{MS}, \mathrm{V}$ is volatility, and $\mathrm{F}$ is the proportion of fragmentation of VOC $x$ to ion $y$.

245 To confirm that this value was consistent, a simple linear regression was performed

246 between the intensity of ion $y$ and $X$, the sum of the corrected AUCs (equation (2)).

$$
X=\sum_{1}^{N} A U C_{i} \times V_{i} \times F_{i, y}
$$

248

249

250

251

252

253

254

255

256

257

258

259

260

261

262

263

264

265

266

A linear regression was performed using the data on the 40 bread types, by bootstrapping 30 randomized lines (1000 iterations). The $R^{2}$ distributions of these linear regressions were plotted, and the mean $R^{2}$ was calculated.

The $\%$ contribution was weighted by the percentage of $Y$ explained by $X$ as expressed by the $R^{2}$ value (when mean $R^{2}>0.5$ ) according to the following equation (3):

$$
\% \text { contribution }(x, y)=100 \times R^{2} \times \frac{A U C_{x} \times V_{x} \times F_{x, y}}{\sum_{1}^{N} A U C_{i} \times V_{i} \times F_{i, y}}
$$

This value was calculated for each bread type. The means and standard deviations for the nine bread types used in the in vivo study are presented in Table 3.

Kinetics of ion release. Ion release curves were drawn using PTR-MS software (Ionicon Analytik, Innsbruck, Austria). The background noise was removed by subtracting the mean signal for the ambient air and the mean signal for the participant's breath from the signal obtained during oral processing. Since the objective was to compare ion release kinetics among bread types, arbitrary units (intensity in ion counts per second [cps]) were used. The following variables were calculated from each individual release curve and for each ion: maximum intensity (Imax), the time at which maximum intensity occurred (Tmax), and the total area under the curve (AUC). A three-way ANOVA followed by a multiple comparisons test was performed using the PTR-MS data $(p<0.05$, Fisher's LSD test). The model included bread type (the nine breads), sample type (CO vs. CC), participant identity (ID), and the following interactions: bread type*sample type, bread 
267 type*participant ID, and sample type*participant ID. Since the differences between the 268 CO and CC samples were highly significant, we also performed two-way ANOVAs on the 269 CO and CC datasets separately to study the differences among bread types; the models 270 included bread type, participant ID, and bread type* participant ID.

271 TDS data. Sensation dominance, expressed as a percentage, was calculated at each 272 point in time: it was the relative frequency of a given attribute being described as 273 dominant by the participants. These percentages were smoothed using the Bézier 274 procedure in Fizz Traitement software and were plotted against standardized time $(0=$ 275 start of mastication and $100=$ end of perceived sensations). The curves for all the 276 attributes were plotted on the same graph, along with the "chance level" line and the 277 "significance level" line. ${ }^{29}$

278 EMG data. The following variables were calculated from the EMG curves: number of 279 bites, chewing frequency $\left(\mathrm{s}^{-1}\right)$, mean burst duration (ms), mean EMG activity (mean of 280 the peak areas per masticatory cycle averaged across the four muscles; $\mu \mathrm{V} . \mathrm{s}$ ) and total 281 EMG activity (sum of the peak areas for all the masticatory cycles averaged across the 282 four muscles; mV.s). ${ }^{30}$ A three-way ANOVA followed by a multiple comparisons test $(p<$ 283 0.05, Fisher's LSD test) was performed; the model included bread type, sample type, 284 participant ID, and all possible interactions.

\section{Results}

\section{Bread crumb properties}

288 The nine breads differed in the structural properties and VOC profiles of their crumbs 289 (Table 1 and Figure 1). Figure 1 displays the results of the MFA, notably the variable 290 correlation circle (Figure 1.a) and bread position along axes 1 and 2 (Figure 1.b). Bread 291 types B1, B2, and B3 had significantly higher crumb water content than the other bread 
292 types. They had also larger amounts of the main VOC ion fragments. Bread type b3_T, a 293 traditional bread from a bakery (b3), had the firmest, densest crumb. Breads B2 and S_O 294 had the least dense crumb. On average, the crumb of the three ordinary breads (b1_O1, 295 b1_O2, and S_O) was less dense and more dry than that of the three traditional breads 296 (b1_T, b2_T, and b3_T). Moreover, the ordinary breads had very similar crumb structures and VOC profiles; the traditional breads showed greater differentiation. Among the parbaked breads, breads B1 and B3 were similar in crumb structure, while breads B2 and B3 had similar crumb VOC profiles.

300

\section{Relative VOC contributions to target ions}

To identify the ions to monitor, the contributions of each VOC to ion production were determined based on the linear regression between the amount of a given ion, as measured by PTR-MS, and the sum of the amount of contributing VOCs, as measured by GC-MS (Table 3). The calculations were based on data for the crumb samples of the nine bread types. As expected, $m / z 47$ was closely associated with ethanol $\left(R^{2}=0.78\right)$; indeed, it is the main ion produced by the protonation of ethanol during PTR-MS. ${ }^{9,22}$ This result confirms that it is possible to relate the GC-MS data to the PTR-MS data. The $\mathrm{R}^{2}$ values of the linear regressions for $\mathrm{m} / \mathrm{z} 57$ and 87 were significantly higher than 0.5 , suggesting that each set of VOCs explained most of the variability in each ion's abundance. For example, $\mathrm{m} / \mathrm{z} 57$ could result from any one of $10 \mathrm{VOCs}$ found in bread crumb, but in this study, it was mainly related (58\%) to 2-methyl-1-propanol, which was found in the nine bread types used. This VOC is produced during fermentation, occurs in large quantities in bread crumb, and is associated with sensory notes such as "glue", "alcoholic", "wine-like", and "malty". ${ }^{31}$ The $m / z \quad 87$ ion seems to result from 2methylbutanal (34\%) and 3-methylbutanal (15\%). In the crumb, these compounds are mainly produced during fermentation (via the Ehrlich pathway); they are also known as 
317 Maillard compounds. ${ }^{32}$ They have been identified as key odorants in baguette crusts with 318 "malty", "almond", and "roasted" notes. ${ }^{31,33}$ For $m / z 45$ and 73, the R $^{2}$ values were higher

319 than 0.5 but not significantly so. Some hypotheses may nonetheless be proposed. The $320 \mathrm{~m} / \mathrm{z} 45$ ion could mainly be produced by acetaldehyde, as observed in other studies. ${ }^{7,34,35}$

321 The $\mathrm{m} / \mathrm{z} 73$ ion could be generated by 2-butanone and 2-methylpropanal, compounds 322 produced by fermentation or Maillard reactions. Finally, the regression results were not 323 significant for $m / z 71,95$, and 97 .

324

325

\section{In vivo release}

Differences in ion release dynamics. In Figure 2, an example of the mean release curves for the different ions across all the participants is provided; the data come from the B1 CO and CC samples. Ion release kinetics differed for the different bread types. The intensities of the $\mathrm{m} / \mathrm{z} 45,47,57$, and 71 ions rose progressively from the time the sample was introduced into the mouth until it was swallowed; they peaked at swallowing for both sample types. Since release dynamics were the same for the $\mathrm{CO}$ and $\mathrm{CC}$ samples, it appears that the presence of crust did not impact their release. Consequently, these ions can be seen as crumb markers. In contrast, $\mathrm{m} / \mathrm{z} 73$ and 87 release differed between the $\mathrm{CO}$ and $\mathrm{CC}$ samples: it was close to nine times higher when crust was present. Moreover, the ions' intensities peaked at the beginning of mastication, just after the sample entered the mouth. Then, they decreased slightly and were not impacted by swallowing. These ions can thus be seen as crust markers. The $m / z 95$ and 97 ions occurred at very low levels in both the CO and CC samples (RSB < 1.5), so their results were not analyzed further.

Differences in VOC release among bread types and sample types. Maximum ion release intensities were determined for each participant for all the bread types and sample types (Figure 3). We observed differences in release profiles among breads for 
342 all the ions detected in the $\mathrm{CO}$ and/or CC samples. In the CO samples, the par-baked

343 breads, especially $\mathrm{B} 1$ and $\mathrm{B} 3$, had the highest maximum intensities for the crumb 344 markers $(\mathrm{m} / \mathrm{z} 45,47,57$, and 71$)$. This result makes sense, given that the initial VOC 345 profiles for the CO samples of these breads were rich in $\mathrm{m} / \mathrm{z} 45,47$, and 57 (Figure 1). In

346 the CC samples, the par-baked breads had the lowest maximum intensities for the crust

347 markers ( $\mathrm{m} / \mathrm{z} 73$ and 87$)$. Their crusts were probably poorer in Maillard compounds than

348 those of the other breads. The intensities of $\mathrm{m} / \mathrm{z} 73$ and 87 were highest in bread b1_O2,

349 suggesting, for example, it was subject to more intensive baking than the others. Finally,

350 there was no clear distinction between ion intensities in ordinary versus traditional breads

351 for either the CO or CC samples.

352 Differences in ion release among participants. Individuals differed in their ion release 353 dynamics (Figure 4). Participants \#1 and \#7 had low maximum intensities for all the ions 354 (except $\mathrm{m} / \mathrm{z} 87$ with medium intensity), whereas the opposite was true for participants \#2, 355 \#3, \#4, and \#5. Participants \#6 and \#8 had intermediate maximum intensities across the 356 panel, but the highest intensity of $\mathrm{m} / \mathrm{z} 87$ for participant \#6.

\section{Chewing behavior dynamics}

358 Using EMG, the chewing behavior of three participants (\#1, \#3, and \#8) was 359 characterized as they consumed CO and CC samples of the three par-baked breads (B1, 360 B2, and B3) (Table 4). As expected, some differences were observed between the CO 361 and CC samples. When crust was present, the mean number of bites increased 1.25 to 3621.5 times, and the mean activity required to break down the CC versus the CO samples was 2-fold higher. The three par-baked breads also showed significant differences, which seemed to be driven by bread density and crumb firmness. The densest and firmest

365 bread-B1-was associated with the greatest number of bites, the lowest chewing 366 frequency, the highest mean burst duration, and the highest mean and total EMG activity 
367 for both the CO and CC samples (data not shown). Finally, the participants differed in 368 their chewing behavior. Participant \#1 was a slow eater and displayed an intermediate 369 level of EMG activity. It appears that this individual did not adapt her chewing behavior to sample type because she showed no difference in chewing frequency or mean burst duration for the $\mathrm{CO}$ versus the CC samples. Participant \#3 was also a slow eater but displayed a high level of EMG activity. Participant \#8 consumed all the samples faster than did the two others and had a low level of EMG activity. His mean burst duration was higher than that of the other two, which was suggestive of a different oral management 375 strategy.

\section{Perception dynamics for the three par-baked breads}

377 The dynamics of the dominant sensations associated with the $\mathrm{CO}$ and $\mathrm{CC}$ samples of the 378 three par-baked breads (B1, B2, and B3) were characterized using the TDS method 379 (Figure 5). These three breads were used because they are well characterized, especially with regards to their bolus properties. ${ }^{10,20,21}$ Therefore, clarifying how these breads break down during oral processing could enhance our understanding of perception dynamics. The results show that the different bread types and sample types resulted in different sensations over time.

When participants consumed the CO samples, they perceived all three breads as having dominant "wheat" notes just before swallowing. Furthermore, bread B2 conveyed a dominant "fermented" sensation at the beginning of consumption. Otherwise, there was no agreement among participants with regards to the dominant sensations experienced until the intermediate phase of crumb consumption. After swallowing, "wet flour" and "wheat" notes persisted in association with breads B2 and B3, respectively. When participants consumed the CC samples, they attributed a greater number of 391 dominant attributes to the breads. At the beginning of consumption, they perceived the 
392 three breads as having dominant "toasted" notes. As oral processing proceeded, "roasted 393 cereals" and "cardboard" notes emerged for breads B1 and B2, respectively. For breads 394 B1 and B3, the dominance of "wheat" emerged prior to swallowing, as for the CO samples. In contrast, there were no commonalities between $\mathrm{B} 2 \mathrm{CO}$ and $\mathrm{CC}$ samples.

\section{Discussion}

398

\section{VOC contribution to ion fragments}

To our knowledge, this study is the first to statistically relate ion fragment data obtained using PTR-MS to VOC data obtained using GC-MS with the purpose of quantitating the contributions of VOCs to ion fragments. An important caveat is that the relationships described here are only applicable to the study food: French baguette crumb. For $m / z 71$, 95, and 97, the linear regressions were not significant. There could be different explanations for this finding: (i) all the VOCs capable of generating these ions were not included in the statistical models; (ii) background noise (i.e., excessive variability) could be obscuring the relationship given that both the ions and the VOCs occurred at low levels; and/or (iii) some of the VOCs could display a lesser affinity for the purge-and-trap sorbent (i.e., Tenax ${ }^{\circledR}$ ), skewing their abundance and ratios relative to their actual occurrence in bread. ${ }^{36}$ However, for five of the target ions, the coefficients of determination were high enough that a percentage contribution could be calculated. The results are consistent with those found with data on baker's yeast starters obtained via PTR-MS utilizing a time-of-flight mass analyzer ${ }^{34}$; however, the latter study focused exclusively on VOCs produced during fermentation. In this study, the VOCs produced during both fermentation and baking were examined. This statistical analyses have helped clarify the dynamics behind the ion fragments generated by complex food 
416 products such as bread. It has also shown that ion fragments are not always related to a

417 VOC's protonated ion.

\section{Impact of bread structure and composition on in vivo aroma release}

419 As expected, the release of crumb markers (i.e., $m / z 45,47,57$, and 73 ) during crumb consumption was influenced by the crumb's initial VOC profile. In breads B1, B2, B3, and b1_T, both the initial content and intensity of crumb markers were high. Furthermore, the release of crumb markers was also impacted by crumb firmness. Indeed, breads with high Young's modulus values, such as b3_T or b1_O1, also displayed high intensity values for crumb markers, even though these markers were present at intermediate or low levels. The greater release of crumb markers in breads with firm crumb could be explained by the fact that firm breads induced more intense chewing activity. This result concurs with results found for model cheeses varying in hardness. ${ }^{16}$ So, the high degree

markers had a greater rate of release than did crumb markers. Structural differences between the crumb and the crust could be at the origin of this observation. The soft and elastic crumb is surrounded by the rigid and brittle crust. ${ }^{38,39}$ During consumption, the crust is probably broken down more rapidly than the crumb due to its placement on the brittleness are important factors that can impact the in vivo release of VOCs. They should therefore be accounted for when designing the aromatic properties of breads. 
440 It is well known that individuals vary in their oral processing and thus release aromas

441 differently. ${ }^{17,40}$ Mastication, saliva volume, and saliva composition all have a major

442 impact. ${ }^{41}$ To delve further into aroma release dynamics, we studied the chewing behavior

443 of three of the participants in the in vivo study. The results revealed that greater muscular

444 activity appears to release greater amounts of VOCs. However, although a previous in

445 vitro study ${ }^{10}$ had found that the volume of saliva added to the bolus plays a key role in

446 limiting aroma release, the links were not obvious here. In fact, contrary to expectations,

447 participant \#3, who had a more hydrated bolus than did participants \#1 and \#8, also

448 showed more intense chewing activity and greater levels of ion release (bolus data come

449 from a previous study involving the same three subjects ${ }^{20}$ ). Thus, under in vivo 450 conditions, mastication appears to have a greater effect on aroma release than does

451 salivation. However, this result must be confirmed with a greater number of subjects. In

452 summary, participant physiology affects VOC release. More specifically, intense chewing 453 activity releases greater amounts of VOCs in the oronasal cavity. However, the 454 differences in VOC release were more dramatic among bread types than among 455 participants. A study involving a larger number of subjects would be required to validate 456 these results.

\section{Impact of in vivo aroma release on perception dynamics}

458 Differences in the release of crumb and crust markers could explain the perception 459 dynamics observed via TDS. It was difficult to link a specific marker with a specific 460 attribute, because a perceived aroma is the result of a combination of several VOCs, and 461 all the compounds responsible for generating aroma perceptions were not monitored. 462 Nonetheless, some relationships could be established at the level of sample type. Crumb 463 markers such as acetaldehyde $(\mathrm{m} / \mathrm{z} 45)$, ethanol $(\mathrm{m} / \mathrm{z} 47)$, and 2-methyl-1-propanol $(\mathrm{m} / \mathrm{z}$ 464 57) were progressively released until a sample was swallowed, which is when they 
465

466

467

468

469

470

471

472

473

474

475

476

477

478

479

480

481

482

483

484

485

486

487

488

reached maximum intensity. They could thus contribute to dominant sensations at the end of the mastication phase and post swallowing. These sensations were associated with crumb-specific attributes such as "wheat", "wet flour", or "fermented". In contrast, when crust was present, crust markers such as Strecker aldehydes (2- and 3methylbutanal $[\mathrm{m} / \mathrm{z}$ 87] and 2-methylpropanal $[\mathrm{m} / \mathrm{z}$ 73]) were released in larger quantities from the beginning of mastication. They likely contributed to initial dominant sensations such as "toasted", "roasted cereals", or "cardboard". However, although the release of crumb markers was generally similar between $\mathrm{CO}$ and $\mathrm{CC}$ samples, the B2 CC sample was not perceived as having dominant "wheat" and "wet flour" notes like the B1 and B3 $\mathrm{CC}$ samples at the end of mastication. For B2, this absence could have resulted from the bread's low-density, elastic crumb structure, rapidly broken crust, or a masking effect of the crust's "cardboard" note.

In conclusion, crumb and crust markers were released at different rates, which apparently led to different sequences of sensation dominance between crumb and crust attributes. This study revealed that the initial levels of crumb markers as well as crumb firmness affected crumb markers release, leading to different perception dynamics. Overall, this study underscores that characterizing bread texture is essential for a better understanding volatile release dynamics and, thus, the way in which bread aroma is perceived. These results could help inform the development of new bread types (e.g., via yeast selection or customizing specific steps in the bread-making process) that better target consumer needs and desires. To go further with the project, the effect of crumb and crust structure could have been investigated in in vitro conditions (e.g. using a model -mouth and applying different break forces), in order to get more insights and to eliminate subject variation in chewing. The ion/flavor release during consumption could 
489 have been analyzed with and without chewing, to gain information of static and dynamic

490 flavor release including the effect of saliva and the formation of Strecker Aldehydes.

491

492 Abbreviations

493 APCI-MS, atmospheric pressure chemical ionization-mass spectrometry; PTR-MS, 494 proton transfer reaction-mass spectrometry; VOC, volatile organic compound; TDS, 495 temporal dominance of sensations; EMG, electromyography; ANOVA, analysis of 496 variance; CO, crumb only; CC, crumb with crust.

\section{Acknowledgments}

498 The authors would like to acknowledge Lesaffre International for providing financial 499 support in the form of a PhD grant. We also thank J. Jeandel for her helpful contributions 500 to the in vivo monitoring of aroma release and D. Forest for his technical support. We are

501 grateful to C. Tournier for her precious advice regarding the acquisition and analysis of 502 EMG data. C. Dupuy, E. Guichard, and G. Della Valle are kindly acknowledged for 503 having participated in fruitful discussions with us. Finally, we would like to thank J. 504 Pearce-Duvet for copyediting the manuscript. 


\section{References}

507 (1) Taylor, A. J.; Linforth, R. S. T. Flavour release in the mouth. Trends Food Sci.

(2) Linforth, R.; Martin, F.; Carey, M.; Davidson, J.; Taylor, A. J. Retronasal Transport of Aroma Compounds. J. Agric. Food Chem. 2002, 50, 1111-1117.

(3) Salles, C.; Chagnon, M.-C.; Feron, G.; Guichard, E.; Laboure, H.; Morzel, M.; Semon, E.; Tarrega, A.; Yven, C. In-Mouth Mechanisms Leading to Flavor Release and Perception. Crit. Rev. Food Sci. Nutr. 2011, 51, 67-90.

(4) Buettner, A.; Beauchamp, J. Chemical input - Sensory output: Diverse modes of physiology-flavour interaction. Food Qual. Prefer. 2010, 21, 915-924.

(5) Taylor, A. J. Release and Transport of Flavors In Vivo: Physicochemical, Physiological, and Perceptual Considerations. Compr. Rev. Food Sci. Food Saf. 2002, 1, 45-57.

(6) Taylor, A. J.; Linforth, R. S. T.; Harvey, B. A.; Blake, A. Atmospheric pressure chemical ionisation mass spectrometry for in vivo analysis of volatile flavour release. Food Chem. 2000, 71, 327-338.

(7) Lindinger, W.; Hansel, A.; Jordan, A. On-line monitoring of volatile organic compounds at pptv levels by means of proton-transfer-reaction mass spectrometry (PTR-MS) medical applications, food control and environmental research. Int. J. Mass Spectrom. Ion Process. 1998, 173, 191-241.

(8) Guichard, E.; Salles, C. 1- Retention and Release of Taste and Aroma Compounds from the Food Matrix during Mastication and Ingestion. In Flavor; 2016; pp 3-22.

(9) Buhr, K.; van Ruth, S.; Delahunty, C. Analysis of volatile flavour compounds by Proton Transfer Reaction-Mass Spectrometry: fragmentation patterns and discrimination between isobaric and isomeric compounds. Int. J. Mass Spectrom. 2002, 221, 1-7.

(10) Jourdren, S.; Saint Eve, A.; Pollet, B.; Panouillé, M.; Lejeune, P.; Guichard, E.; Déléris, I.; Souchon, I. Gaining deeper insight into aroma perception: an integrative study of the oral processing of breads with different structures. Food Res. Int. 2017, 92, 119-127.

(11) Heenan, S. P.; Dufour, J.-P.; Hamid, N.; Harvey, W.; Delahunty, C. M. Characterisation of fresh bread flavour: Relationships between sensory characteristics and volatile composition. Food Chem. 2009, 116, 249-257.

(12) Biasioli, F.; Gasperi, F.; Aprea, E.; Endrizzi, I.; Framondino, V.; Marini, F.; Mott, D.; Märk, T. D. Correlation of PTR-MS spectral fingerprints with sensory characterisation of flavour and odour profile of "Trentingrana" cheese. Food Qual. Prefer. 2006, 17, 63-75.

(13) Frank, D. C.; Eyres, G. T.; Piyasiri, U.; Delahunty, C. M. Effect of food matrix structure and composition on aroma release during oral processing using in vivo monitoring. Flavour Fragr. J. 2012, 27, 433-444.

(14) Repoux, M.; Labouré, H.; Courcoux, P.; Andriot, I.; Sémon, É.; Yven, C.; Feron, G.; Guichard, E. Combined effect of cheese characteristics and food oral processing on in vivo aroma release. Flavour Fragr. J. 2012, 27, 414-423.

(15) Labouré, H.; Repoux, M.; Courcoux, P.; Feron, G.; Guichard, E. Inter-individual retronasal aroma release variability during cheese consumption: Role of food oral processing. Food Res. Int. 2014, 64, 692-700.

(16) Tarrega, A.; Yven, C.; Sémon, E.; Salles, C. Aroma release and chewing activity during eating different model cheeses. Int. Dairy J. 2008, 18, 849-857. 
554 (17) Gierczynski, I.; Laboure, H.; Guichard, E. In Vivo Aroma Release of Milk Gels of Different Hardnesses: Inter-individual Differences and Their Consequences on Aroma Perception. J. Agric. Food Chem. 2008, 56, 1697-1703.

(18) Onishi, M.; Inoue, M.; Araki, T.; Iwabuchi, H.; Sagara, Y. A PTR-MS-Based Protocol for Simulating Bread Aroma During Mastication. Food Bioprocess Technol. 2012, 5, $1228-1237$.

(19) Landgraf, F. Produits et procédés de panification. In Techniques de l'ingénieur; 2002; Vol. F6180.

(20) Jourdren, S.; Panouillé, M.; Saint-Eve, A.; Déléris, I.; Forest, D.; Lejeune, P.; Souchon, I. Breakdown pathways during oral processing of different breads: impact of crumb and crust structures. Food Funct. 2016, 7, 1446-1457.

(21) Jourdren, S.; Saint-Eve, A.; Panouillé, M.; Lejeune, P.; Déléris, I.; Souchon, I. Respective impact of bread structure and oral processing on dynamic texture perceptions through statistical multiblock analysis. Food Res. Int. 2016, 87, 142151.

(22) Fiches, G.; Saint Eve, A.; Jourdren, S.; Déléris, I.; Brunerie, P.; Souchon, I. Temporality of perception during the consumption of French grape brandies with different aging times in relation with aroma compound release. Flavour Fragr. J. 2016, 31, 31-40.

(23) Lenfant, F.; Loret, C.; Pineau, N.; Hartmann, C.; Martin, N. Perception of oral food breakdown. The concept of sensory trajectory. Appetite 2009, 52, 659-667.

(24) van Ruth, S.; Boscaini, E.; Mayr, D.; Pugh, J.; Posthumus, M. Evaluation of three gas chromatography and two direct mass spectrometry techniques for aroma analysis of dried red bell peppers. Int. J. Mass Spectrom. 2003, 223-224, 55-65.

(25) Mayr, D.; Märk, T.; Lindinger, W.; Brevard, H.; Yeretzian, C. Breath-by-breath analysis of banana aroma by proton transfer reaction mass spectrometry. Int. J. Mass Spectrom. 2003, 223-224, 743-756.

(26) Wang, T.; Španěl, P.; Smith, D. A selected ion flow tube, SIFT, study of the reactions of $\mathrm{H} 3 \mathrm{O}+, \mathrm{NO}+$ and $\mathrm{O} 2+$ ions with several $\mathrm{N}$ - and $\mathrm{O}$-containing heterocyclic compounds in support of SIFT-MS. Int. J. Mass Spectrom. 2004, 237, 167-174.

(27) Biasioli, F.; Gasperi, F.; Aprea, E.; Colato, L.; Boscaini, E.; Märk, T. D. Fingerprinting mass spectrometry by PTR-MS: heat treatment vs. pressure treatment of red orange juice-a case study. Int. J. Mass Spectrom. 2003, 223-224, 343-353.

(28) Španĕl, P.; Van Doren, J. M.; Smith, D. A selected ion flow tube study of the reactions of $\mathrm{H} 3 \mathrm{O}+, \mathrm{NO}+$, and $\mathrm{O} 2+$ with saturated and unsaturated aldehydes and subsequent hydration of the product ions. Int. J. Mass Spectrom. 2002, 213, 163176.

(29) Pineau, N.; Schlich, P.; Cordelle, S.; Mathonnière, C.; Issanchou, S.; Imbert, A.; Rogeaux, M.; Etiévant, P.; Köster, E. Temporal Dominance of Sensations: Construction of the TDS curves and comparison with time-intensity. Food Qual. Prefer. 2009, 20, 450-455.

(30) Tournier, C.; Grass, M.; Septier, C.; Bertrand, D.; Salles, C. The impact of mastication, salivation and food bolus formation on salt release during bread consumption. Food Funct. 2014, 5, 2969-2980.

(31) Pico, J.; Gómez, M.; Bernal, J.; Bernal, J. L. Analytical methods for volatile compounds in wheat bread. J. Chromatogr. A 2016, 1428, 55-71.

(32) Birch, A. N.; Petersen, M. A.; Hansen, A. S. REVIEW: Aroma of Wheat Bread Crumb. Cereal Chem. J. 2014, 91, 105-114.

(33) Zehentbauer, G.; Grosch, W. Crust aroma of baguettes I. Key odorants of baguettes prepared in two different ways. J. Cereal Sci. 1998, 28, 81-92. 
604

605

606

607

608

609

610

611

612

613

614

615

616

617

618

619

620

621

622

623

624

625

626

627

628

(34) Makhoul, S.; Romano, A.; Cappellin, L.; Spano, G.; Capozzi, V.; Benozzi, E.; Märk, T. D.; Aprea, E.; Gasperi, F.; El-Nakat, H.; et al. Proton-transfer-reaction mass spectrometry for the study of the production of volatile compounds by bakery yeast starters: PTR-MS study of bakery yeast starters. J. Mass Spectrom. 2014, 49, 850859.

(35) Ting, V. J. L.; Romano, A.; Silcock, P.; Bremer, P. J.; Corollaro, M. L.; Soukoulis, C.; Cappellin, L.; Gasperi, F.; Biasioli, F. Apple Flavor: Linking Sensory Perception to Volatile Release and Textural Properties. J. Sens. Stud. 2015, 30, 195-210.

(36) Maeda, T.; Kikuma, S.; Araki, T.; Ikeda, G.; Takeya, K.; Sagara, Y. The effects of mixing stage and fermentation time on the quantity of flavor compounds and sensory intensity of flavor in white bread. Food Sci. Technol. Res. 2009, 15, 117-126.

(37) Gao, J.; Wong, J. X.; Lim, J. C.-S.; Henry, J.; Zhou, W. Influence of bread structure on human oral processing. J. Food Eng. 2015, 167, 147-155.

(38) Scanlon, M. G.; Zghal, M. C. Bread properties and crumb structure. Food Res. Int. 2001, 34, 841-864.

(39) Chaunier, L.; Chiron, H.; Della Valle, G.; Saulnier, L. Evaluation instrumentale de la texture contrastée croûte/mie de pains miniaturisés présentant des teneurs en fibres variées. Ind. Céréal. 2008, 160, 2-8.

(40) Repoux, M.; Sémon, E.; Feron, G.; Guichard, E.; Labouré, H. Inter-individual variability in aroma release during sweet mint consumption. Flavour Fragr. J. 2012, $27,40-46$.

(41) van Ruth, S. M.; Roozen, J. P. Influence of mastication and saliva on aroma release in a model mouth system. Food Chem. 2000, 71, 339-345. 


\section{Figure captions:}

630 Figure 1: Correlation circle (a) and the graphical representation of bread type features (b) 631 along axes 1 and 2 in the multiple factor analysis (MFA) performed on structural data (in 632 red) and PTR-MS data (in blue) for the crumb of the nine bread types. The target ions 633 from the in vivo analyses are represented with open symbols.

634 Figure 2: Example mean release curves for the eight target ions; they were generated 635 using data for crumb-only (CO) and crumb-with-crust (CC) samples of bread type B1. 636 Intensity (in counts per seconds [cps]) was plotted against consumption time (s). The 637 mean swallowing time (ST) is indicated by the vertical line.

638 Figure 3: Mean maximum intensities (Imax, in cps) and the associated standard errors $639(\mathrm{n}=24)$ for the nine bread types (for crumb-only [CO] or crumb-with-crust [CC] samples). 640 The letters a through e indicate when means differed significantly among bread types 641 (Fisher's LSD test; $p<0.05)$.

642 Figure 4: Mean maximum intensities (Imax, in cps) and the associated standard errors $643(n=54)$ for the eight study participants. The letters a through e indicate when means 644 differed significantly among participants (Fisher's LSD test; $p<0.05$ ).

645 Figure 5: Temporal patterns of sensation dominance for crumb-only (CO) samples (on 646 the left) and crumb-with-crust (CC) samples (on the right) during consumption. Time was

647 standardized ( $\%$ of time available for perception). SL = significance line; $C L=$ chance 648 line; ST = swallowing time. 


\section{Tables}

Table 1: Physical properties of the nine studied breads assessed in triplicates. Product effect was determined by a one-way ANOVA. Letters a to $g$ indicate means that significantly differ between products at $p<0.05$ (Fisher's LSD test).

\begin{tabular}{llcccc}
\hline $\begin{array}{l}\text { Bread } \\
\text { code } \\
\text { name }\end{array}$ & Origin & Type & Density & $\begin{array}{c}\text { Water content of } \\
\text { crumb }\end{array}$ & $\begin{array}{c}\text { Young's modulus } \\
\text { of crumb }\end{array}$ \\
& & & $(-)$ & $\begin{array}{c}\text { (g per 100 } \mathrm{g} \text { of } \\
\text { crumb) }\end{array}$ & $(\mathrm{kPa})$ \\
\hline B1 & Laboratory & Par-baked & $0.273 \pm 0.001 \mathrm{a}$ & $51.5 \pm 0.2 \mathrm{a}$ & $15.0 \pm 4.1 \mathrm{~b}$ \\
B2 & Laboratory & Par-baked & $0.164 \pm 0.001 \mathrm{~g}$ & $49.3 \pm 0.1 \mathrm{~b}$ & $3.8 \pm 0.9 \mathrm{e}$ \\
B3 & Laboratory & Par-baked & $0.220 \pm 0.003 \mathrm{c}$ & $50.6 \pm 0.1 \mathrm{a}$ & $12.5 \pm 0.6 \mathrm{bc}$ \\
S_O & Supermarket & Ordinary & $0.164 \pm 0.001 \mathrm{~g}$ & $45.4 \pm 0.3 \mathrm{e}$ & $7.8 \pm 0.9 \mathrm{cde}$ \\
b1_O1 & Local bakery 1 & Ordinary & $0.180 \pm 0.002 \mathrm{e}$ & $46.6 \pm 1.8 \mathrm{~d}$ & $11.0 \pm 4.2 \mathrm{bcd}$ \\
b1_O2 & Local bakery 1 & Ordinary & $0.171 \pm 0.001 \mathrm{f}$ & $47.1 \pm 0.3 \mathrm{~cd}$ & $7.1 \pm 4.6 \mathrm{de}$ \\
b1_T & Local bakery 1 & Traditional & $0.216 \pm 0.002 \mathrm{c}$ & $48.2 \pm 0.5 \mathrm{bc}$ & $11.5 \pm 3.5 \mathrm{bcd}$ \\
b2_T & Local bakery 2 & Traditional & $0.192 \pm 0.001 \mathrm{~d}$ & $48.5 \pm 0.3 \mathrm{~b}$ & $5.7 \pm 1.1 \mathrm{e}$ \\
b3_T & Local bakery 3 & Traditional & $0.265 \pm 0.006 \mathrm{~b}$ & $46.6 \pm 0.5 \mathrm{~d}$ & $25.3 \pm 2.1 \mathrm{a}$ \\
\hline
\end{tabular}


Table 2: lons that were monitored during in vivo PTR-MS measurements.

\begin{tabular}{clccc}
\hline$m / z$ ion & Chemical formula & Dwell time $(\mathrm{ms})$ & Series 1 & Series 2 \\
\hline 21 & $\mathrm{H}_{2} \mathrm{O}, \mathrm{H}^{+}$ & 50 & $\mathrm{x}$ & $\mathrm{x}$ \\
37 & $\left(\mathrm{H}_{2} \mathrm{O}\right)_{2}, \mathrm{H}^{+}$ & 50 & $\mathrm{x}$ & $\mathrm{x}$ \\
45 & - & 100 & $\mathrm{x}$ & \\
47 & $\mathrm{C}_{2} \mathrm{H}_{5} \mathrm{OH}, \mathrm{H}^{+}$ & 100 & $\mathrm{x}$ & \\
57 & - & 100 & $\mathrm{x}$ & \\
59 & $\mathrm{C}_{3} \mathrm{H}_{6} \mathrm{O}, \mathrm{H}^{+}$ & 50 & $\mathrm{x}$ & $\mathrm{x}$ \\
71 & - & 100 & $\mathrm{x}$ & \\
73 & - & 100 & & $\mathrm{x}$ \\
87 & - & 100 & & $\mathrm{x}$ \\
95 & - & 100 & & $\mathrm{x}$ \\
97 & $\mathrm{C}_{5} \mathrm{H}_{4} \mathrm{O}_{2}, \mathrm{H}^{+}$ & 100 & & $\mathrm{x}$ \\
\hline
\end{tabular}


Table 3: Percentage of contribution of VOCs (with a molar mass $M$ ) to the corresponding fragments, calculated by taking the volatility $(\mathrm{V})$, the proportion of fragmentation into the corresponding ion $(F)$ of each VOC and the mean $R^{2}$ of the linear regression between $X$ (sum of the quantities of VOCs measured by purge and trap) and $Y$ (quantity of the ion measured in vitro by PTR-MS) into account. Compounds were identified based on their linear retention indices and mass spectra. We used a mass standard MS database: the Wiley Registry of Mass Spectral Data. Identification was not confirmed by standard injection. The volatility (V) was characterized by Henry's law constant (partition coefficient of VOCs between air and water at $25^{\circ} \mathrm{C}$ ), calculated using the EPI Suite's experimental database. The proportion of fragmentation $(F)$ was founded in literature. If not the maximal coefficient was chosen $\left(100\right.$, in italic). SD = standard deviation of $R^{2}$.

\begin{tabular}{|c|c|c|c|c|c|c|c|}
\hline $\mathrm{m} / \mathrm{z}$ & $\begin{array}{l}\text { VOC (tentatively } \\
\text { identified by GC-MS) }\end{array}$ & $\begin{array}{c}\mathrm{M} \\
\left(\mathrm{g} \cdot \mathrm{mol}^{-1}\right)\end{array}$ & $\begin{array}{c}\mathrm{V}^{3} \\
\left(\mathrm{~atm} \cdot \mathrm{m}^{3} / \mathrm{mol}\right)\end{array}$ & $\begin{array}{l}F \\
(\%)\end{array}$ & $\mathrm{R}^{2}$ & SD & $\%$ contribution \\
\hline \multirow[b]{2}{*}{45} & acetaldehyde & 44 & 6.78E-05 & $100^{25}$ & \multirow[b]{2}{*}{0.520} & \multirow[b]{2}{*}{0.077} & $43 \pm 5$ \\
\hline & $\begin{array}{l}\text { 2-methylbutanal } \\
\text { 2-pentanone } \\
\text { 2-heptanol }\end{array}$ & $\begin{array}{c}86 \\
86 \\
116\end{array}$ & $\begin{array}{l}1.59 \mathrm{E}-04 \\
8.73^{\mathrm{E}}-05 \\
2.34^{\mathrm{E}}-05\end{array}$ & $\begin{array}{l}32^{*} \\
82^{y} \\
100\end{array}$ & & & $\begin{aligned} 8 & \pm 5 \\
& <1 \\
& <1\end{aligned}$ \\
\hline 47 & ethanol & 46 & $5.67^{\mathrm{E}}-06$ & $70^{9}$ & 0.780 & 0.049 & 78 \\
\hline \multirow{10}{*}{57} & 2-methyl-1-propanol & 74 & $9.99^{\mathrm{E}}-06$ & $100^{28}$ & \multirow{10}{*}{0.823} & \multirow{10}{*}{0.079} & $58 \pm 24$ \\
\hline & 2-propenal & 56 & $3.58^{\mathrm{E}}-05$ & $100^{2 b}$ & & & $10 \pm 13$ \\
\hline & nonanal & 142 & $4.93^{t}-04$ & $9^{y}$ & & & $6 \pm 19$ \\
\hline & 1-butanol & 74 & $9.99^{t}-06$ & $90^{y}$ & & & $<5$ \\
\hline & 1-pentanol & 88 & $1.33^{\mathrm{E}}-05$ & $89^{y}$ & & & $<5$ \\
\hline & 1-hexanol & 102 & $1.76^{\mathrm{E}}-05$ & $16^{y}$ & & & $<5$ \\
\hline & 1-hydroxypropan-2-one & 74 & $1.73^{\mathrm{E}}-06$ & 20 * & & & $<1$ \\
\hline & 1-heptanol & 116 & $2.34^{E}-05$ & 100 & & & $<1$ \\
\hline & 2-heptanol & 116 & $2.34^{\mathrm{E}}-05$ & 100 & & & $<1$ \\
\hline & 1-octen-3-ol & 128 & $2.31^{t}-05$ & $3^{y}$ & & & $<1$ \\
\hline \multirow{5}{*}{71} & 2-butenal & 70 & $5.61^{E}-05$ & $100^{28}$ & \multirow{5}{*}{0.318} & \multirow{5}{*}{0.096} & \\
\hline & 3-hydroxybutan-2-one & 88 & $1.03^{\mathrm{t}}-05$ & 100 & & & \\
\hline & 2-methylbutanol & 88 & $1.33^{\mathrm{E}}-05$ & 100 & & & \\
\hline & 3-methylbutanol & 88 & $1.33^{\mathrm{E}}-05$ & $39^{y}$ & & & \\
\hline & 2-pentanol & 88 & $1.33^{\mathrm{t}}-05$ & $39^{25}$ & & & \\
\hline \multirow{3}{*}{73} & 2-butanone & 72 & $6.58^{\mathrm{E}}-05$ & $100^{9}$ & \multirow{3}{*}{0.609} & \multirow{3}{*}{0.126} & $38 \pm 8$ \\
\hline & 2-methylpropanal & 72 & $1.20^{\mathrm{E}}-04$ & $100^{28}$ & & & $18 \pm 10$ \\
\hline & tetrahydrofuran & 72 & $8.43^{\mathrm{E}}-05$ & $77^{26}$ & & & $<5$ \\
\hline \multirow{8}{*}{87} & 2-methylbutanal & 86 & $1.59^{\mathrm{E}}-04$ & 49 * & \multirow{8}{*}{0.622} & \multirow{8}{*}{0.116} & $34 \pm 9$ \\
\hline & 3-methylbutanal & 86 & $1.59^{\mathrm{t}}-04$ & 10 * & & & $15 \pm 6$ \\
\hline & pentanal & 86 & $1.59^{\mathrm{E}}-04$ & $5^{y}$ & & & $9 \pm 11$ \\
\hline & 2-pentanone & 86 & $8.73^{\mathrm{E}}-05$ & $85^{y}$ & & & $<5$ \\
\hline & 2,3-butanedione & 86 & $1.97^{\mathrm{E}}-07$ & $89^{y}$ & & & $<1$ \\
\hline & 3-methylbut-3-en-1-ol & 86 & $1.55^{\mathrm{E}}-05$ & 1 * & & & $<1$ \\
\hline & 1-penten-3-ol & 86 & $9.88^{\mathrm{E}}-06$ & 100 & & & $<1$ \\
\hline & 2-penten-1-ol & 86 & $1.17^{\mathrm{E}}-05$ & 100 & & & $<1$ \\
\hline \multirow{3}{*}{95} & methylpyrazine & 94 & $3.22^{\mathrm{E}}-06$ & $100 *$ & \multirow{3}{*}{0.185} & \multirow{3}{*}{0.120} & \\
\hline & phenol & 94 & $5.61^{\mathrm{t}}-07$ & 98 * & & & \\
\hline & 2,3-pentanedione & 100 & $2.62^{\mathrm{E}}-07$ & 3 * & & & \\
\hline 97 & furfural & 96 & $3.77^{\mathrm{E}}-06$ & 96 * & 0.429 & 0.131 & \\
\hline
\end{tabular}


Table 4: Chewing activity parameters measured by electromyography for crumb only (CO) and crumb with crust (CC) samples of B1, B2 and B3 breads and for 3 panelists. Mean and standard deviation of number of bites, chewing frequency, mean burst duration, mean EMG activity and total EMG activity. Letters a to e indicate means that significantly differ between panelists and samples at $p<0.05$ (Fisher's LSD test).

\begin{tabular}{|c|c|c|c|c|c|c|c|}
\hline & & CO samples & & & CC samples & & \\
\hline & & Panelist \#1 & Panelist \#3 & Panelist \#8 & Panelist \#1 & Panelist \#3 & Panelist \#8 \\
\hline Bite number & - & $49 \pm 6 b$ & $41 \pm 2 c$ & $25 \pm 3 e$ & $61 \pm 7 a$ & $61 \pm 6 a$ & $34 \pm 4 d$ \\
\hline Chewing frequency & $s^{-1}$ & $1.46 \pm 0.06 a b$ & $1.34 \pm 0.08 c$ & $1.40 \pm 0.07 b$ & $1.47 \pm 0.04 a$ & $1.41 \pm 0.09 a b$ & $1.46 \pm 0.07 a$ \\
\hline Mean burst duration & $\mathrm{ms}$ & $284 \pm 16 d$ & $339 \pm 19 b$ & $381 \pm 31 a$ & $274 \pm 17 d$ & $310 \pm 9 c$ & $326 \pm 15 b$ \\
\hline Mean EMG activity & $\mu \mathrm{V} . \mathrm{s}$ & $26 \pm 7 c$ & $29 \pm 6 c$ & $17 \pm 2 d$ & $44 \pm 4 b$ & $59 \pm 7 a$ & $39 \pm 1 b$ \\
\hline Total EMG activity & mV.s & $1.30 \pm 0.41 c$ & $1.22 \pm 0.26 c$ & $0.44 \pm 0.09 d$ & $2.66 \pm 0.38 b$ & $3.60 \pm 0.70 a$ & $1.33 \pm 0.41 c$ \\
\hline
\end{tabular}


Figure 1.a

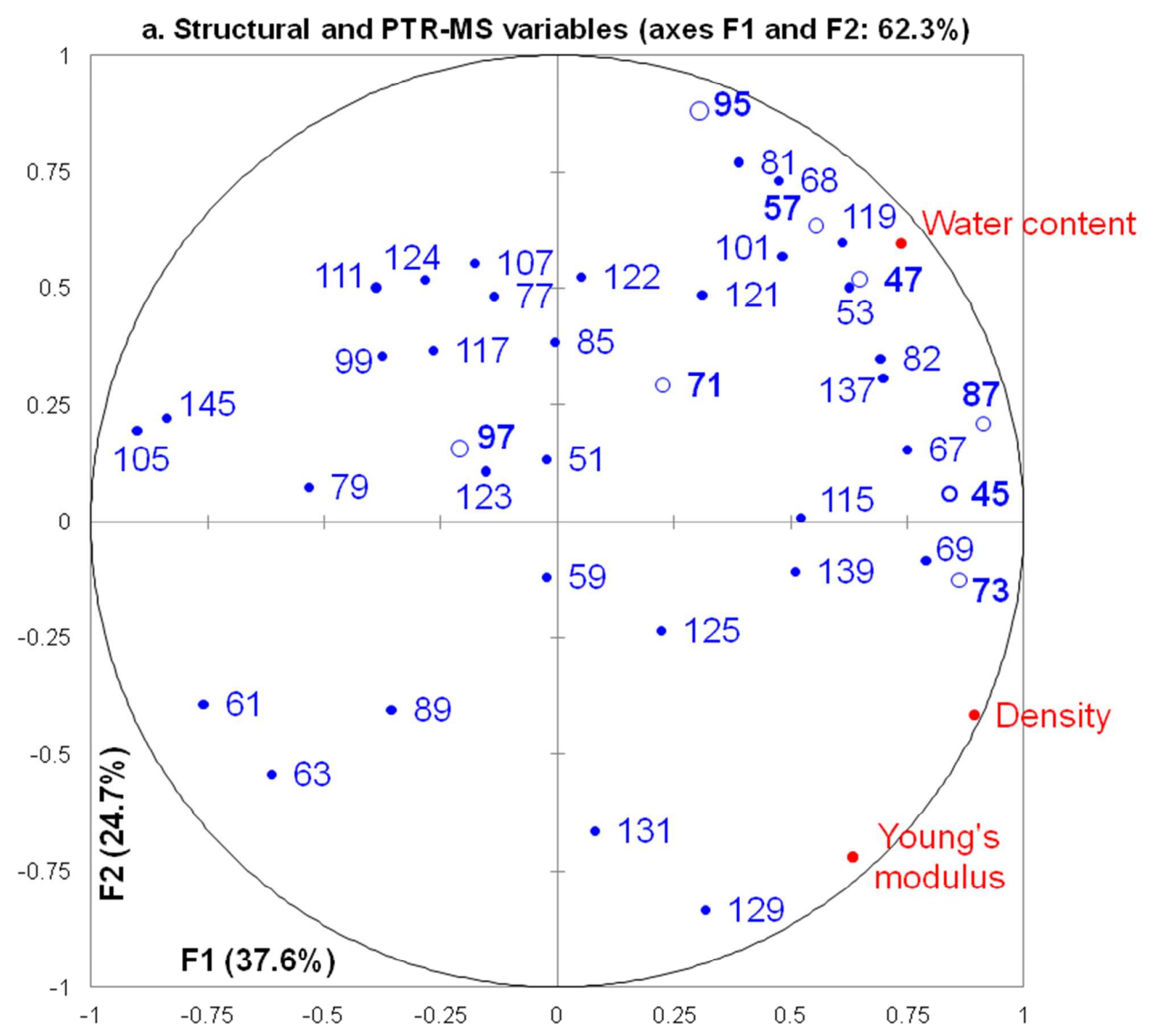


Figure 1.b

b. Bread types (axes F1 and F2: 62.3\%)

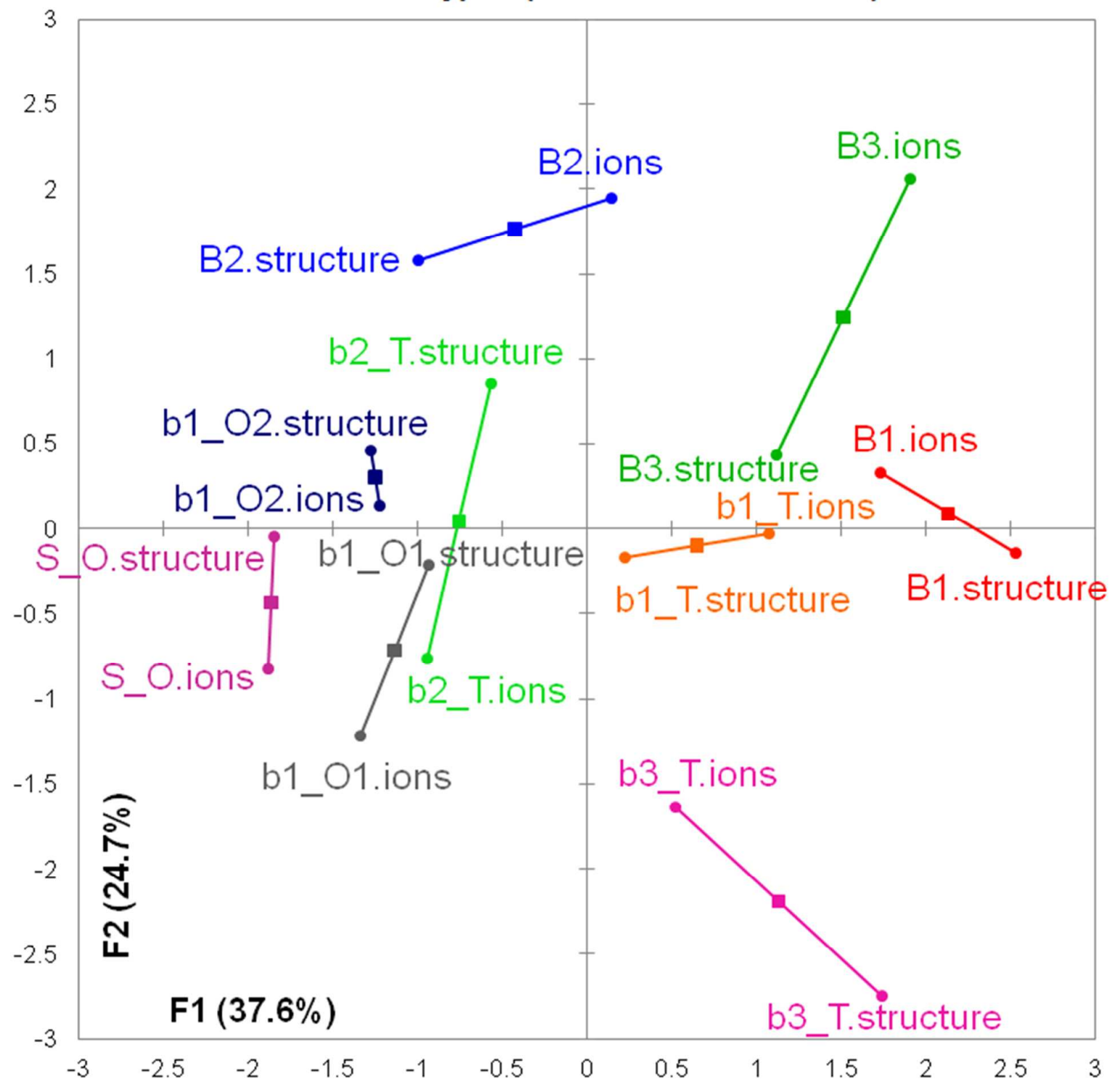




\section{Figure 2}
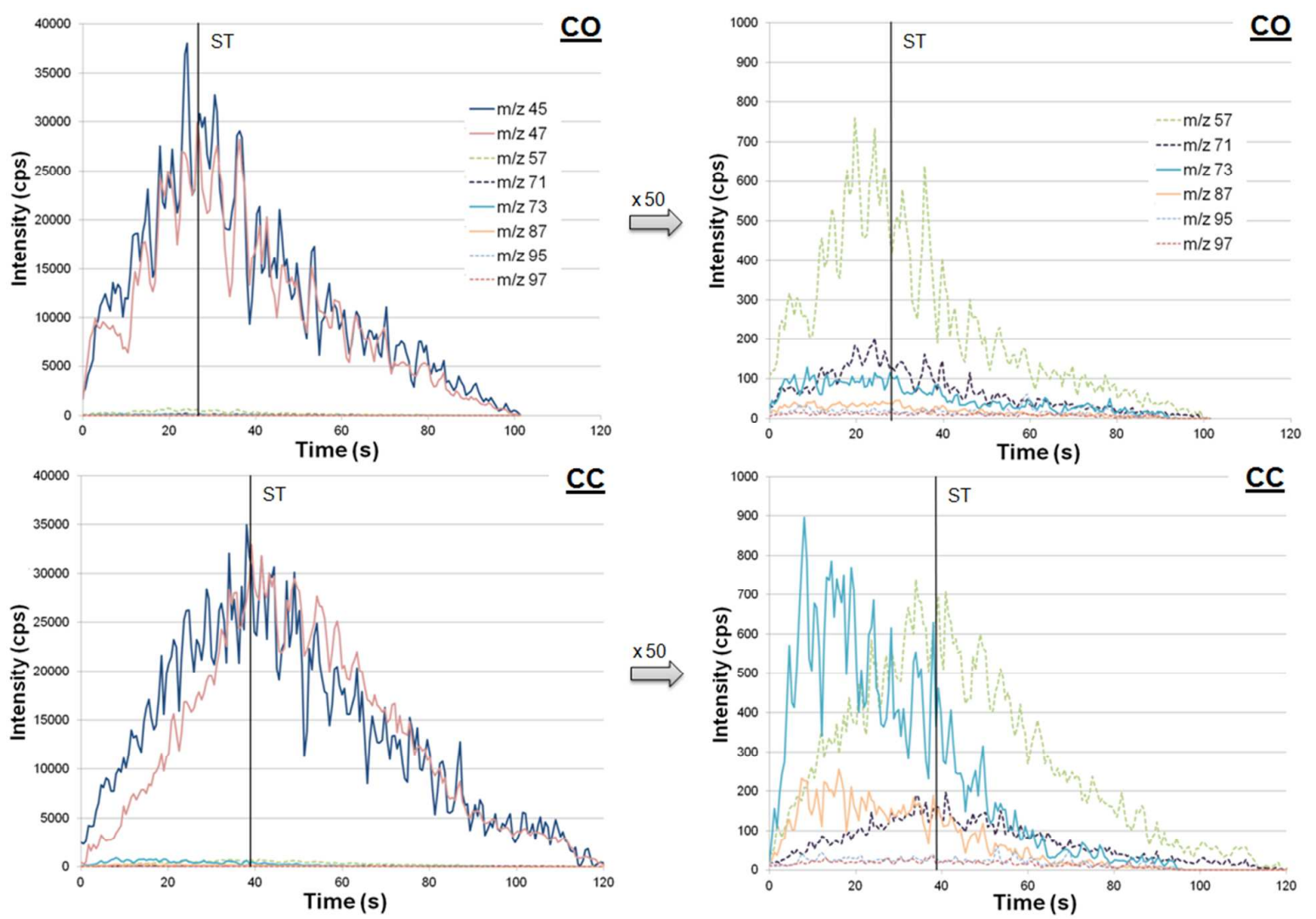


\section{Figure 3}
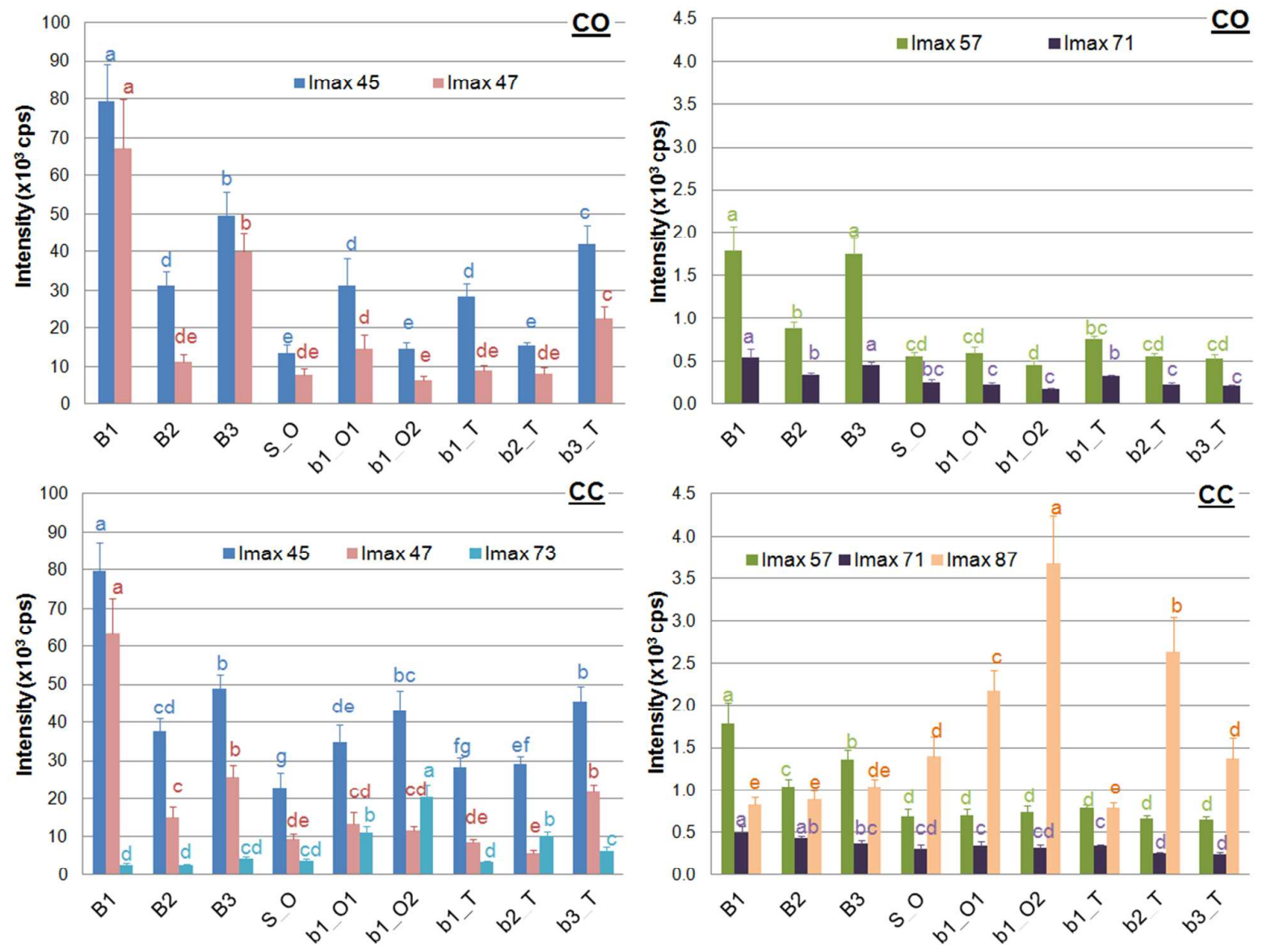


\section{Figure 4}
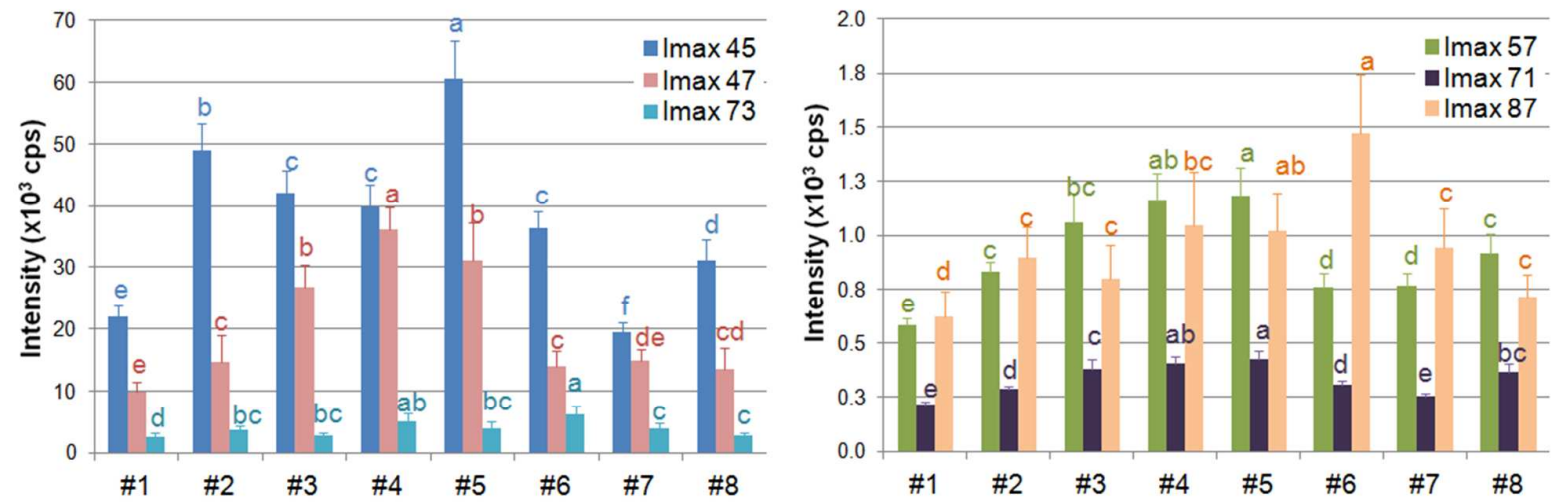


\section{Figure 5}
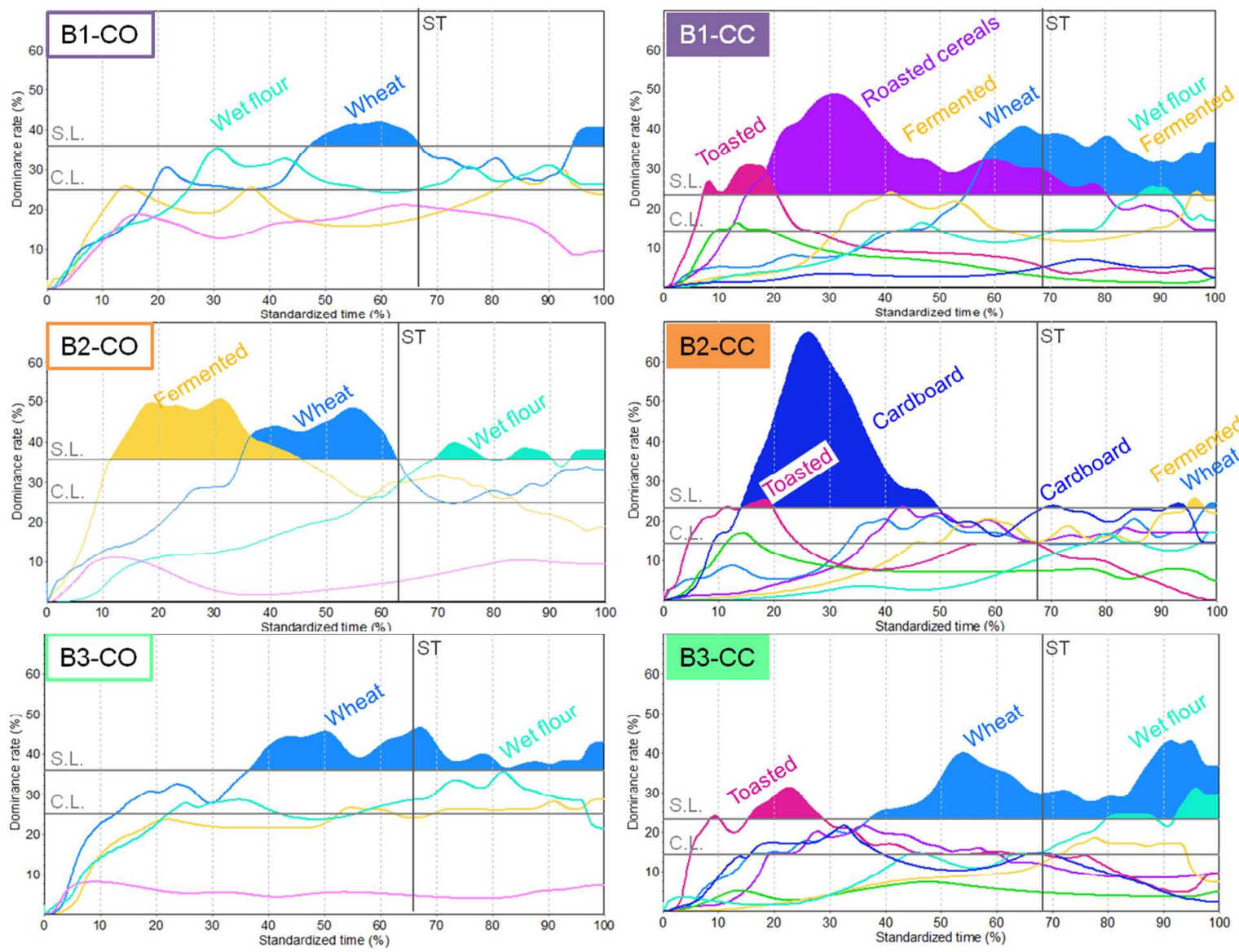


\section{TOC graphic}

Dynamics of bread aroma perception are related to aroma release in the oral cavity (for crumb with crust samples)
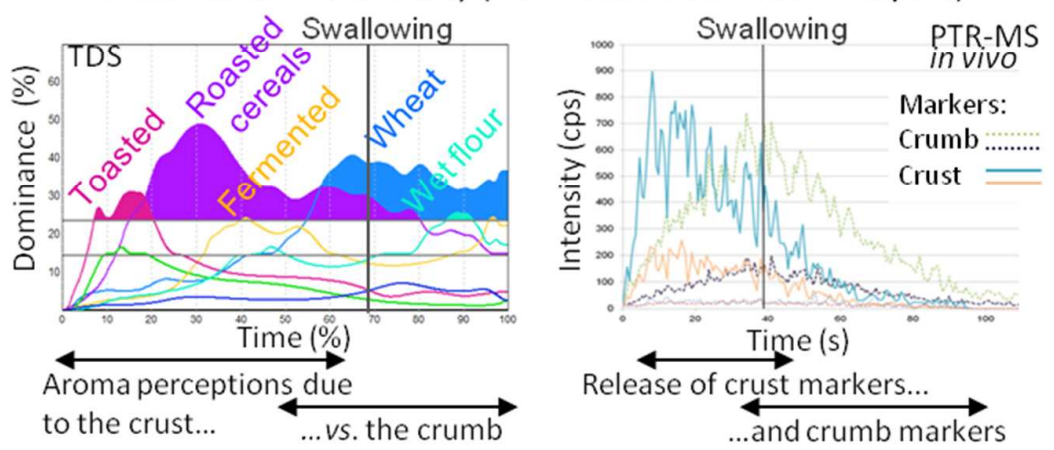